\title{
MOVIMENTOS SOCIAIS E EDUCAÇÃO: UMA RELAÇÃO FECUNDA ${ }^{1}$
}

\author{
Social Movements and Education: \\ A Prolific Relation
}

Sandra Luciana Dalmagro²

\begin{abstract}
Resumo
O artigo versa sobre a formação humana gerada nos Movimentos Sociais, em particular no Movimento dos Trabalhadores Rurais Sem Terra - MST, tendo por base revisão de literatura sobre o tema, bem como estudos anteriores e experiências da autora junto a Movimentos Sociais. Parte-se do entendimento de que a educação não se descola da base material e do conjunto social no qual se encontra, e que, portanto, mudar a educação é mudar a realidade mesma. Os Movimentos Sociais são expressão das contradições sociais ao mesmo tempo em que são portadores de futuro. Neste sentido, dão base à educação que se distancia da perspectiva burguesa, tateando em seu interior novas relações. Na atualidade vê-se a crescente concentração da riqueza e do poder, mas também a pulverização de lutas, coletivos e movimentos que de diferentes formas questionam as estruturas sociais e educacionais vigentes, lançando esperança em tempos sombrios. O MST é um importante Movimento Social para pensar a atualidade pois questiona a propriedade privada dos meios de produção, ensaiando novas formas de produzir a vida em seu interior, abrigando uma multiplicidade de temas, processo este formador da consciência social. O MST e os coletivos em emergência na atualidade indicam que os Movimentos Sociais e a educação são tão históricos quanto as sociedades e relações que os engendram.
\end{abstract}

Palavras-chave: Movimentos Sociais; Trabalho; Educação; Lutas Sociais; MST.

\section{Abstract}

This article is about the human formation generated from the Social Movements, specially the one on the Landless Workers Movement. This article has literature review about the subject as well as previous researches and experiences from the author together to Social Movements. The article comes from the understanding that education doesn't occur apart from the material basis and from society in wich is in. Therefore changing the education is to

\footnotetext{
1 Texto escrito a propósito da mesa intitulada "A formação dos trabalhadores no espaço de trabalho, de moradia, na escola e nos Movimentos Sociais", realizada no III INTERCRíTICA Intercâmbio Nacional dos Grupos de Pesquisa em Trabalho e Educação da ANPED, Curitiba, setembro de 2016.

2 Professora do Centro de Ciências da Educação da UFSC. sandradalmagro@yahoo.com.br

TrabalhoNecessario - www.uff.br/trabalhonecessario; Ano 14, № 25/2016
} 
change the reality itself. The Social Moviments are the the expressions of social contradictions and at the same time bringing a new time. They give the basis to a education which gets far from the dominant perspective, building new relationships. Nowadays its touchable the increasing wealthy concentration and Power, but also the social struggle's pulverization, collective and movements that from different formats questionate the educational and social structures in force, giving some hope in dark times. MST is an important social moviment to think the the present moment due to its questionings about private property in the production ways, reharsing many forms to produce life in itself, covering a range of topics. This process is responsable for social conciousness. MST and the collectives in emergency presently show that Social Moviments and the education are so historical as the societies and the relationships that engender themselves.

Key-Words: Social Movements; Work; Education; Social Struggles; Landless Workers Movement.

\section{Introdução}

Pensar a formação dos trabalhadores e em particular a formação gerada nos Movimentos Sociais é pensar a realidade mesma, uma vez que a base na qual nos educamos coincide com aquela em que provemos nossa existência. Este texto pretende sustentar a tese de que nossa educação provém do meio em que vivemos, das relações que estabelecemos e que, portanto, mudar a educação é mudar a realidade social. Os Movimentos Sociais são expressão dos limites e das contradições da sociedade atual e são, portanto, profundamente educativos uma vez que por sua atuação simultaneamente questionam as estruturas sociais e a educação delas proveniente, oferecendo pistas para novas formas de organização da vida social e da educação.

O texto começa com alguns apontamentos breves acerca da realidade atual para então pensar a questão educacional tendo por base o materialismo histórico dialético. Na sequência, refletimos a questão educacional tendo por referência um movimento social específico, o Movimento dos Trabalhadores Rurais Sem Terra - MST. Por fim agregamos elementos dos protestos, movimentos e coletivos que emergiram nos anos recentes, considerando que estes não apenas apontam as contradições do presente bem como contém indicações sobre o futuro. 
Não é o propósito deste texto realizar uma análise da estrutura social na qual nos encontramos ou uma análise da conjuntura nesta fase imperialista do capital (FONTES, 2010, HARVEY, 2014), porém não podemos nos furtar de aí enraizar nossa análise acerca da formação humana e do sentido dos Movimentos Sociais pois este é o meio que os gera, para ou contra o qual se dirigem e onde reside portanto a possibilidade de melhor explicá-los. Faremos portanto, brevemente alguns apontamentos.

Segundo dados da $\mathrm{FAO}^{3}$, em 2010 ultrapassamos a marca de um bilhão de famintos no globo, o que entra em franca contradição com o desenvolvimento de poderosas formas produtivas. As condições de moradia e saneamento de imensas parcelas da população mundial são igualmente graves. Segundo Davies (2006), em países pobres como Bangladesh, Etiópia e Sudão a porcentagem da população vivendo em favelas ultrapassa a $80 \%$; no Brasil são 51,7 milhões de pessoas, $36,6 \%$ dos brasileiros. O desemprego é fenômeno estrutural e global, a atingir países ricos ou pobres, cidade e campo. As populações indígenas e tradicionais são continuamente expulsas de suas terras ou impossibilitadas de nelas subsistir. Segundos da CPT (2015) só em 2015 no Brasil foram registrados 1.227 conflitos por terra, água e relações degradantes de trabalho no campo envolvendo mais de 800 mil pessoas. Em âmbito internacional guerras são promovidas submetendo países inteiros a esta lógica, produzindo milhares de famintos, despatriados, vítimas da violência, gerando uma das maiores migrações em massas em pleno século XXI. Mulheres, jovens, crianças, negros e idosos são força de trabalho ainda mais barata e precarizada, além de vítimas mais freqüentes de todo tipo de violência. Os agrotóxicos envenenam a comida dos humanos e o meio ambiente, mas engordam as receitas das empresas que os produzem. Tornase mercadoria a educação, a saúde, a água, as sementes, o conhecimento. Nada parece escapar à lógica do mercado, como já anunciara Marx (1999).

No caso brasileiro, a precarização da escola pública e a propriedade dos meios de comunicação de massa entre as elites são condições indispensáveis para manutenção deste sistema, uma das sociedades mais desiguais do mundo. Com tantas e tamanhas contradições, o controle ideológico e da informação são cada vez mais necessários, o que não dispensa, claro, o uso

\footnotetext{
3 Organização das Nações Unidas para Agricultura e Alimentação.
}

TrabalhoNecessario - www.uff.br/trabalhonecessario; Ano 14, № 25/2016 
da força. Nos dois casos temos muitos exemplos como o Projeto de Lei "Escola Sem Partido", a condenação jurídica das greves e a violência policial aos que denunciam e se manifestam contra esta situação.

O capitalismo mundializou-se, a riqueza e o poder se encontram concentradas em cada vez menor número de pessoas ou corporações, enquanto a população de todos os continentes e países vai sendo submetida a esta lógica. $1 \%$ da população mundial concentra tanta riqueza quanto os $99 \%$ restantes $^{4}$, o que fora o principal mote dos protestos conhecidos como Ocuppy iniciado em Wall Street em 2011 e que se espalharam por boa parte do mundo. Como conseqüência desta centralização temos estabelecido, ainda que sem reconhecimento oficial, mas na prática, um "governo do mundo", comandado pelos que controlam a economia global e articulam-se em torno dos grandes bancos e agências internacionais. Para Harvey (2014), a espoliação dos recursos naturais de nações e povos torna-se imprescindível para continuar a acumulação de capital, impondo aos países e às suas populações suas regras e leis, as quais cada vez mais se colocam em direção contrária aos interesses soberanos das nações e às necessidades de sobrevivência digna de sua população. Neste sentido, é cada vez mais transparente que vivemos em um mundo que opõe os interesses de um seleto grupo de super ricos contra o conjunto da população mundial. A concentração da riqueza que já fora tão admirada e desejada inclusive pelos que não a tinham, tem passado a ser denunciada e condenada moralmente, como atestam o crescimento dos protestos contra o sistema do capital ao redor do globo. Se o capital possui enorme poder de controle sobre o mundo, numa demonstração de sua força, eis que aí também se encontra sua fraqueza.

Expressão das contradições, talvez como em nenhuma outra época existam tantas mobilizações, coletivos e organizações os quais atuam nos mais variados temas e lugares (HARVEY et all, 2012; MARICATO el all, 2013; CAROS AMIGOS, 2016). Ambientais e alimentares, por moradia e transporte, na comunicação e jornalismo, nas artes e na cultura, sem terra e sem teto, por

\footnotetext{
${ }^{4}$ http://www.bbc.com/portuguese/noticias/2016/01/160118 riqueza estudo oxfam fn. Acesso em 9/9/2016 as 10:51. O site afirma ainda que 62 pessoas mais ricas do mundo acumulam 0 equivalente à riqueza dos $50 \%$ mais pobres da população mundial, indicando uma concentração de riqueza impressionante e galopante considerando que em 2010 , o equivalente à riqueza da metade mais pobre da população global estava na mão de 388 indivíduos.
}

TrabalhoNecessario - www.uff.br/trabalhonecessario; Ano 14, № 25/2016 
creche, escola e saúde pública, de mulheres, negros e de orientação sexual, na música e na internet, de estudantes e operários. A pulverização de temáticas que parece não comportar unidade, não teria por base uma mesma realidade social cada vez mais controlada, homogeneizada e mercantilizada? A luta pela diversidade não seria expressão de que vivemos num mundo cada vez mais homogêneo? (JAMESON, 2006). A defesa do direto de expressão, comunicação e informação independentes não indica a concentração dos mesmos? Defendemos os direitos de trabalhadores, mulheres, negros, homossexuais e migrantes, enfim, os direitos humanos porque estes se encontram ameaçados? A realidade social desenrola-se contraditoriamente. $\mathrm{O}$ capitalismo gera o seu contrário, a luta por sua superação.

A outra face da concentração da riqueza e do poder, e sua conseqüente padronização cultural é, neste momento da história, o sem número de lutas, organizações, coletivos e movimentos dos mais variados tipos, formas de organização e ação. A variedade de propósitos, formas de articulação, mobilização e táticas de ação torna a expressão Movimento Social imprecisa. Para evitar a indefinição, tomamos a indicação de Kula (1977), para quem Movimentos Sociais são aqueles que fazem a contestação da sociedade vigente, portanto, aqueles que lutam por transformação nas estruturas sociais. O termo movimentos sociais foi criado nos anos 1840 por Von Stein, sociólogo e economista alemão, para analisar o mundo urbano-industrial e refere-se às ações coletivas de um determinado grupo organizado que visa alcançar mudanças na sociedade. Neste sentido pensamos que os movimentos captam o sensível da sociedade, expressam seus limites, suas necessidades de mudança, dão pistas do futuro, portanto, também são férteis para pensar a educação.

\section{Formação humana: de onde vem nossa educação?}

Nascemos da espécie homo sapiens sapiens, mas precisamos aprender a ser homens (Figueira, 1985). Aprendemos no meio em que vivemos, nas relações que estabelecemos. A educação não se descola da vida real, ela se processa na vida real e esta tem por fundamento a produção da existência, o trabalho. Para Marx (1987), o determinante ou a centralidade da formação do 
homem e de seu processo de conhecimento encontra-se na atividade humana, no trabalho, na práxis. Diferentemente de idealistas e empiristas para quem o homem aprende pela razão ou pelos sentidos, Marx joga a centralidade para o terreno da história, para a atividade humana que molda a razão e os sentidos.

Para Suchodolski (1976), Marx se opôs às correntes idealistas que compreendiam o homem como dotado de uma essência inata e imutável, mas também criticou o empirismo, ainda que o considerasse um avanço em relação à teoria metafísica tradicional da essência, uma vez que, para aquele, não se poderia atribuir nenhum apriorismo ao homem, este era uma tábua rasa. Para o empirismo, o ser do homem advém do ambiente cujos sentidos humanos são capazes de captar. Marx critica essa perspectiva, considerando-a de caráter antissocial e metafísica. Para Suchodolski,

não se trata de modo nenhum de uma ponte secreta que através dos sentidos ponha em comunicação dois mundos opostos - o mundo dos homens e o mundo das coisas. Tratase de uma relação de mútuo contacto e de mútuo condicionamento, de uma relação de criação e transformação recíproca (1976, p. 16).

Marx demonstra nos Manuscritos Econômicos e Filosóficos (1987) que a formação dos sentidos humanos é trabalho de sucessivas gerações. Os órgãos humanos possuem a capacidade de ver, ouvir, falar, sentir, mas o que vêem, ouvem, falam e sentem é produto social e histórico Os sentidos humanos ensinam sobre o mundo objetivo, mas são formados por este mundo. As correntes pedagógicas sensualistas destacam o papel do ambiente na educação, mas ignoram o papel da ação humana nesse ambiente, assim, a mudança pela educação do ambiente se torna impossível. Lukács (1967) indica que autores burgueses, já no início do século $X X$, pretendiam salvar a integridade da pessoa humana, contra a retaliação sofrida no processo de trabalho, sem, no entanto, alterar esse processo. Incorrem assim numa crítica moral, abstrata ou na utopia. Esta última, para Mészáros (2006) é "inerente a todas as tentativas que oferecem remédios puramente parciais para problemas globais" (p. 270). Resulta deste processo que se deviam transformar, não as relações sociais, mas a maneira de conceber a existência individual e o ideal, causas destas contradições (SUCHODOLSKI, 2002, p. 98). 
Ressalta-se portanto, a indissocialibilidade entre vida e educação. Viver é o mesmo processo de educar-se, ao produzir a vida produz-se a educação do homem, a forma como produz sua existência diz do processo educativo. A educação é inerentemente social e fundamental à existência humana e "não um processo mais ou menos inútil do qual a sociedade possa prescindir" (FIGUEIRA, 1985). Para este autor, o processo educativo consiste, em última instância, em transformar os indivíduos de um determinado grupo social em participantes de tal sociedade, isto é, comungando o modo de vida, os valores e as relações socialmente vigentes. O objetivo da educação é a inserção social, não de uma forma qualquer, mas de uma forma social, histórica. Precisamos aprender a viver numa sociedade determinada. A educação não é, desta forma, uma abstração, mas produto de relações concretas. Há portanto, para cada época histórica "aquilo que é mais apropriado para se aprender e para se ensinar. Uma época determinada não ensina uma qualquer coisa, um corpo qualquer de saber. Ensina aquilo que pode e deve ensinar" (FIGUEIRA, 1985, p.13). O ensinar nasce, portanto, "com as relações reais dos indivíduos" (idem p. 14).

Mészáros (2005, p. 25), ao apontar os vínculos dos processos educativos com os processos de reprodução social, conclui que o sistema educacional só pode sofrer mudanças profundas com uma transformação correspondente no interior de um quadro social em que tais práticas educacionais se inserem. Para Manacorda (2007), o homem plenamente desenvolvido está situado em Marx, num quadro em que a totalidade das forças produtivas é dominada pela totalidade dos indivíduos livremente associados, possibilitando a cada indivíduo se apropriar do acúmulo histórico da humanidade. É subjacente aos escritos de Marx a descrença de que por meio da educação seria possível superar a divisão do trabalho ou das classes sociais ou mesmo promover a formação omnilateral. É a supressão da propriedade privada dos meios de produção, com o consequente fim das classes e da divisão destas em formas distintas de trabalho que dá bases para o desenvolvimento omnilateral.

O enraizamento da educação nas relações sociais, na base material, possibilita o questionamento da visão idealista de que a mudança do mundo adviria de uma mudança em nossa educação. Poderíamos nos educar de um modo diverso mantendo a mesma base social, sem alterar as relações que nos 
formam? Pensamos que não. Mudar a educação é mudar a realidade mesma. Mas como mudar a realidade se somos educados por ela? A resposta reside, a nosso ver, na compreensão da realidade como totalidade contraditória, em movimento. Esta questão já fora posta por Marx: "por um lado, é necessário modificar as condições sociais para criar um novo sistema de ensino; por outro, falta um sistema de ensino novo para poder modificar as condições sociais. Consequentemente, é necessário partir da situação atual" (MARX e ENGELS, 2004, p. 107).

A situação atual, como apontamos, comporta agudas contradições cada vez mais explosivas. São os limites postos em cada atualidade que empurram às lutas, aos protestos e aos movimentos; são os limites e contradições para produção da vida que exigem a mudança das circunstâncias. Os antagonismos sociais geram interesses opostos. Projetos sociais distintos necessitam de projetos formativos diferentes. As classes em luta originam projetos sociais e educacionais antagônicos, ou ao menos diferentes. Eis a base material sobre a qual uma nova educação ou a consciência de classe se ancora: as lutas, a organização coletiva, a teoria revolucionária, a experiência de classe (THOMPSON, 1987).

Os movimentos sociais geram uma pressão - inclusive educacional sobre a sociedade vigente. A constituição, trajetória e luta dos movimentos, dos partidos, dos grupos, enfim, da classe, são educativos, educam pela ação e organização coletiva. Neste sentido e em perspectiva dialética, é importante observar que, se a educação é originada na base material, na ação humana, portanto ela também age ou retroage sobre esta base, a educação, determinada pelo real, também o determina. Como afirmamos, ela não é um apêndice inútil, ela é essencial para qualquer sociedade ou projeto social. É importante esta observação para não esterilizar o papel da educação, para compreender a práxis humana como prática sensível, como afirma Marx (1989) nas Teses sobre Feuerbach.

Os movimentos sociais são portanto educativos, mais precisamente, ao questionarem as estruturas sociais por meio de suas ações, lutas, organização coletiva. Ao colocarem as pessoas em movimento, em outras circunstâncias e relações, possibilitam alterar a direção da educação. Neste sentido parece correto pensar que quanto mais radical (no sentido de ir à raiz dos problemas 
sociais), quanto mais atinge as causas estruturais do sistema, e isto na prática social e não apenas no âmbito do discurso, maior o potencial de transformação radical da educação.

A "educação virada para o futuro" (SUCHODOLSKI, 2002) não aceita o atual estado de coisas, ultrapassa o horizonte burguês. É somente através da participação na luta para criar um mundo humano que a geração jovem pode verdadeiramente se formar, afirma Suchodolski. É nesse quadro que a educação pode ajudar efetivamente na transformação do mundo. Se referindo à educação escolar afirma: "O ensino só pode atualmente servir o futuro quando vai unido à prática revolucionária que cria este futuro". A vinculação da educação com a prática revolucionária é que resolve a questão do que deve mudar primeiro, se as circunstâncias ou os homens. "Este é o caminho pela qual a educação pode ajudar realmente e não utopicamente a fazer o futuro" (1976, p.178). A teoria de Marx da vinculação do ensino dos homens que se transformam transformando as circunstâncias constitui-se um princípio diretivo fundamental e inesgotável.

Antes de passarmos à próxima parte é importante dizer algo sobre a formação teórica, pois o que afirmamos até o momento pode parecer a alguns que apenas a prática educa e portanto haveria um menosprezo à teoria, o que seria um equívoco. Evitamos a dissociação teoria e prática; a teoria decorre e se articula à prática, a ilumina, dá sentido e coerência. Pensamos com Lênin que sem teoria revolucionária não há prática revolucionária, e que o inverso também é verdadeiro. Os movimentos e organizações que alcançaram maior poder de transformação social não deixaram a elaboração e formação teórica de lado, antes a combinam com a formação originada das lutas. A formação teórica sem atuação concreta, sem enraizamento prático é tão impotente quanto uma prática esvaziada de teoria.

\section{Formação humana e formação da classe no MST}

O MST é fruto da histórica concentração da terra no Brasil, a qual por sua vez, não é desarticulada do desenvolvimento econômico, social e político do país (FERNANDES, 2006, IANNI, 2004). É produto de um momento histórico do capitalismo em âmbito mundial, em sua fase madura, ou imperialista. De 
outro lado, o MST também é produto da organização e luta dos sem terra, de sua capacidade organizativa, de seu contraponto ao capitalismo no campo, enfim, como constituinte da classe trabalhadora, cujas formas de luta e organização adquirem dinâmicas próprias possibilitadas e forjadas em cada contexto. O Movimento é uma forma de reação dos trabalhadores e desempregados (do campo e da cidade) para o combate ao capital e para a necessidade de construção de formas de vida para além deste. O MST, por sua atuação, indica que a luta de classes não deixou de existir, mas que ela assume outros contornos, se transfigura dialeticamente em sintonia com as mudanças operadas na totalidade do modo de produção do capital.

Entendemos o MST como um movimento que aglutina alguns dos milhares de pessoas que não encontram na forma de organização social vigente as condições para produzir sua existência. Muitos dos sem terra que vão ao MST encontram-se despidos de qualquer forma de propriedade: a terra, a moradia e mesmo sua força de trabalho não consegue mais encontrar comprador. São milhares de famílias que vivem à beira das estradas, em barracos, ou nas favelas, vivendo de favor na casa de parentes, agregados e assalariados rurais que quando dispensados de seu trabalho não têm para onde ir. Assim, o MST é um espaço onde milhares de seres humanos buscam uma forma de produção da vida, de inserção social.

Vendramini (2004) considera que no MST uma "massa totalmente destituída de propriedade" constitui um sujeito social coletivo, "uma identidade social que se refere à sua natureza de classe". Num tempo em que a propriedade está altamente concentrada e toda sorte de misérias atinge amplas massas, o movimento social organizado "é capaz de dar condução política à revolta e ao desespero" (VENDRAMINI, 2004, p. 18).

O sem terra vai ao MST não porque deseja transformar a sociedade, mas porque precisa sobreviver; busca uma possibilidade de incluir-se socialmente. Pode até considerar essa forma de sociedade injusta, excludente, da qual ele é vítima, mas a preocupação fundamental é sua sobrevivência e de sua família. Manter-se vivo é condição fundamental e pressuposto para poder fazer a história. ${ }^{5}$ Tomada nesse sentido, a luta de muitos sem terra individualmente é a

\footnotetext{
5 "As premissas de que partimos não são bases arbitrárias, dogmas; são bases reais que só podemos abstrair na imaginação. São os indivíduos reais, ação e suas condições materiais de

TrabalhoNecessario - www.uff.br/trabalhonecessario; Ano 14, № 25/2016
} 
busca pela inserção na sociedade, que acaba por contribuir na reprodução e "reciclamento" da produção de capital. É preciso ter presente que a dimensão corporativa nos limites do capital é real na luta concreta operada pelos semterra organizados no MST, mas não é (não tem sido) única. Na busca por melhores condições de vida dentro da ordem do capital, ou no caso dos sem terra por sua inserção na dinâmica do modo de produção burguês, surge a possibilidade através da atuação, neste caso do movimento social, de superação da luta particular para adentrar a esfera da luta coletiva, de interesses universais dos trabalhadores. É o amadurecimento da luta política dos trabalhadores que permite a ampliação da luta pela sobrevivência individual para chegar à luta pela transformação social. A passagem de um nível a outro, ou a aquisição da consciência de classe se torna possível por meio da "ligação estrutural da experiência do trabalho e das experiências políticas, sociais e educativas" que são gestadas no Movimento Sem Terra (VENDRAMINI, 2000). O MST é então o produto mais acabado do capital, que expressa suas contradições, a máxima capacidade produtiva com a mínima capacidade de socialização da riqueza, é expressão da degeneração dessa sociedade que coloca aos homens a necessidade de sua superação dessa forma de vida social.

A principal forma de luta utilizada pelo MST são as ocupações de latifúndios e os acampamentos nele instalados, cuja presença de centenas ou mesmo milhares de famílias exerce grande pressão por sua desapropriação. A ocupação e os acampamentos são ações de grande radicalidade pois questionam a propriedade privada da terra. Por isso são tão combatidos pela classe dominante e seus aparatos, que buscam inviabilizá-los das mais diversas formas. As marchas e as ocupações de prédios públicos são outras formas importantes de luta utilizadas que também visam pressionar para a realização de suas reivindicações, promover o debate público e a politização.

As principais formas de luta são também as principais formadoras da consciência. A luta coletiva contém um potencial educativo ou formativo

existência, tanto as que eles já encontraram prontas, como aquelas engendradas de sua própria ação. Essas bases são pois verificáveis por via puramente empírica. A primeira condição de toda história humana é, naturalmente, a existência de seres humanos vivos. A primeira situação a constatar é, portanto, as relações que ele gera entre eles e o restante da natureza" (MARX E ENGELS, 1989, p. 37).

TrabalhoNecessario - www.uff.br/trabalhonecessario; Ano 14, № 25/2016 
enorme, pois possibilita ou fomenta o questionamento das bases de sustentação da sociedade que são também as bases sob as quais a consciência ou a educação se constituem. O sem terra compreende sua condição de oprimido na ocupação e no acampamento, quando identifica que esta condição não é individual, mas coletiva. A ocupação é um momento de formação ou despertar da consciência ao questionar a propriedade privada da terra, ao colocar massas humanas destituídas de propriedade no confronto com o capitalista e o Estado. A ocupação é uma ação radical; somente é possível pela ação coletiva, organizada, planejada, consciente. Por detrás da ocupação há um trabalho de formação, um trabalho que contém a solidariedade de classe, empurrada pelas condições degradantes de vida, um processo coletivo e individual, pois cada participante da ocupação também precisa tomar a decisão de nela estar. Está dada então a possibilidade de articular sua condição objetiva e pessoal à organização coletiva e comum.

O período de acampamento, mais duradouro do que a ocupação, também é fértil e fundamental para a promoção de outro tipo de educação, pois nele o conflito entre sem terras e o capitalista permanece visível, assim como o papel da polícia, do judiciário, da mídia e dos poderes locais. No acampamento se constitui um coletivo dos destituídos de propriedade que se reconhecem enquanto tal, que se identificam em suas histórias, que constroem uma identidade coletiva e que pode tornar-se uma identidade de classe. É um período em que o sem terra se defronta com novas relações, com novas experiências de vida em sociedade, as decisões são tomadas coletivamente em assembléias, o alimento e as roupas são distribuídos equitativamente, os núcleos são a organização de base na qual todos fazem parte, espaço de informação, discussão e decisão. É preciso aprender a viver em coletivo e de modo mais igualitário, muitas vezes em direção contrária à educação já consolidada. Aprender novas relações exige atenção, exercício e algum tempo. Não é uma aprendizagem espontânea nem puramente discursiva.

Os acampamentos se destacam ainda pela pluralidade de questões que fazem emergir; a família toda esta na luta em tempo integral, emergem então questões ligadas à infância, às mulheres, ao alcoolismo, à fome, ao analfabetismo, à saúde, ao trabalho, ao meio ambiente... Enfim, toda a complexidade da vida humana emerge no acampamento e coletivamente 
passa a ser gerida, as pessoas são educadas nestas relações que tentam se constituir como novas. Encontramos ações no MST que dizem respeito à organização da moradia, às relações de gênero e entre filhos e pais, à educação escolar e à formação humana, à produção agropecuária para subsistência, para o comércio e na dimensão ecológica, à arte e ao lúdico, à sexualidade, apenas para citar algumas. Essas dimensões incorporadas pelo movimento social acreditamos representar um avanço significativo em relação à esquerda tradicional, limitada aos aspectos corporativos e econômicos, vinculada ao trabalhador empregado e com dificuldades de abarcar em sua luta os desempregados.

No MST, a gestação de novas experiências de organização da vida humana em sua totalidade representam um desafio ao se ter em frente a superação do velho modo capitalista de produzir a vida. Desafio urgente pois, mesmo com a destruição das forças produtivas (MESZAROS, 2002) e a recriação permanente de trabalho, milhares de pessoas não conseguem produzir sua existência no capitalismo, apontando o limite desta forma de sociedade dar conta das necessidade de vida e desenvolvimento humano. São estes limites que empurram as pessoas aos protestos e movimentos sociais onde dão vazão à suas demandas. Coletivos e movimentos podem tatear no presente relações que no futuro podem se consolidar, neste sentido são portadores de futuro.

As relações e embates vividos no acampamento e sentido da luta do MST necessitam, para serem eficazes, de formação teórico-política e de educação escolar como elementos indispensáveis para uma visão mais ampla e articulada de mundo e para o aprofundamento do entendimento da realidade e das estratégias de ação. Educação formal, ainda que contraditoriamente, e formação política autônoma, promovida pela organização da classe, são indispensáveis na luta social. A formação advinda da teoria e da prática podem se enlaçar e quando isto acontece, a consciência social encontra-se melhor sustentada. O estudo sistemático do real, a articulação entre formação teórica e a de base empírica se encontram presentes para que um Movimento Social da envergadura do MST possa existir, perpassa a preparação da ocupação, permite orientar o tenso e longo período de acampamento e depois abre-se em um leque de temas nos assentamentos. Nestes, além da formação política, em 
sentido estrito, se faz necessária também a formação para o trabalho, a cooperação, a agroecologia, a educação escolar entre outros aspectos já citados.

No que se refere à educação escolar identificamos que no MST esta é uma questão presente desde os primeiros acampamentos e atravessa toda a trajetória do MST numa interessante articulação entre a luta por escola e o conjunto das lutas do MST (DALMAGRO, 2010). Neste vasto trabalho com escolas destacamos a tentativa do MST em transformar esta instituição para colocá-la em melhor sintonia com as demandas de suas lutas, o que não se constitui como empreendido fácil, mas demonstra que as possibilidades de transformação da escola andam juntas com as lutas por transformação social, como apontou Suchodolski (1976). Nossas pesquisas identificaram ainda uma crescente importância atribuída pelo MST à escolarização, inclusive na expectativa da formação da consciência política, o que por um lado revela a importância da escolarização (no sentido de acesso a conhecimentos sistematizados, capacidade de leitura, escrita e noção das diferentes ciências) como base necessária à formação política, de outro preocupa ao atribuir à escola um papel que esta não consegue sozinha responder. Observamos que a formação política atribuída à escola neste aspecto parece crescer, porém ocorre num momento em que a luta do MST reflui (DALMAGRO, 2010). Pensamos que a formação de militantes ou da consciência de classe pressupõe o enraizamento concreto nas lutas da classe, ainda que a escolarização seja um aspecto indispensável, ela ganha potencialidade quando articulada às lutas e à organização coletiva. São estas que podem promover transformações na escola e que permitem articulá-la a outro projeto educativo e de sociedade.

A formação adquirida na ocupação e no período de acampamento pode continuar a se desenvolver no assentamento, a depender da organização e das lutas que ali se desenvolvem. Porém, a produção coletiva da vida tende a ser mais avançada nos acampamentos do que nos assentamentos onde a propriedade privada dos meios de produção e a lógica do mercado volta a se impor (GRADE, 2000). Os acampamentos são espaços mais livres das amarras do capital, por outro, não são de todo livres destas amarras, em particular quando os acampados precisam vender sua força de trabalho nas 
fazendas e cidades vizinhas para sobreviver (SAPELLI, 2013). Particularmente fazer germinar novas relações produtivas é algo que o MST buscou ensaiar em alguns assentamentos coletivos e cooperativas, mas é aí onde o limite do MST - e da humanidade neste momento histórico - aparece pois, como estabelecer novas relações de trabalho e produção imersos no sistema capitalista? Se o capitalismo não oferece condições dignas de vida para grande parte da humanidade, esta humanidade ainda não foi capaz de criar uma forma de existência que torne o capitalismo obsoleto. Este limite que se faz sentir nas áreas conquistadas pelo MST é o desafio do conjunto dos que sentem os limites desta forma de vida social. Pinassi assim sintetiza a questão que se coloca ao MST passados 30 anos de sua existência:

A contradição da reforma agrária de mercado bateu às portas do movimento, exigindo a incômoda definição entre atender às contingências do mercado, com camponeses-empreendedores integrados ao capitalismo agrário, fomentar uma indigesta luta de classes em seu interior ou perseverar na formação de trabalhadores conscientes de seu papel histórico na construção do socialismo. Eis a sua [do MST] mais profunda tensão interna: pôr em memória as conquistas do passado, defender sua "vocação camponesa", apostar no empreendedorismo de alguns assentamentos, refluir nas lutas e institucionalizar-se; ou denunciar os limites cada vez mais estreitos que o capital, através de instrumentos privados e estatais, impõe a sua existência como alternativa societária - quase sempre problemática - no interior da ordem. Mais, enfrentar, com a positividade que a luta de classes exige, a proletarização de sua base social, convertida num enorme celeiro de força de trabalho disponível para o capital no campo e na cidade. Os caminhos da "revolução na ordem" se esgotaram. As condições atuais da realidade objetiva se definem por um padrão de acumulação essencialmente destrutivo, o que impõe severa crítica a toda e qualquer via de desenvolvimento - incluindo aí o neodesenvolvimentismo - que se venha formular para a reprodução do sistema sócio-metabólico do capital. (PINASSI, $2014, s / p$, grifos no original).

\section{Considerações finais}

Para concluirmos queremos retomar o ponto pelo qual iniciamos, a situação atual, mas agora sob o ângulo das mobilizações e protestos ocorridos nos últimos anos no Brasil e no mundo. Para Carneiro, em 2011 há uma eclosão simultânea e contagiosa de movimentos sociais de protestos em diversas partes do globo. No norte da África contra ditaduras, na Grécia e 
Espanha com greves e ocupações, em Londres nos subúrbios, no Chile na mobilização dos estudantes por educação pública; nos EUA contra os bancos e corporações. O que há em comum nestas lutas é o desemprego e a carestia, a recusa dos espaços institucionais tradicionais, além da ausência de canais reconhecidos de representação e protesto. Tratou-se de uma "catarse política protagonizada especialmente pelas novas gerações" (CARNEIRO, 2012, p. 9).

Para Zizek (2013), manifestações como o Occupy, a Primavera Àrabe, e Junho de 2013 no Brasil, apesar de cada uma ter motivos específicos ligados ao contexto de cada país, elas tem em comum a reação contra as múltiplas facetas da globalização capitalista, um sentimento de desconforto e descontentamento generalizado com o sistema como um todo e não apenas com um ou outro se seus aspectos. Para Alves (2012) trata-se de uma "globalização dos de baixo", cuja enorme diversidade exprime a universalização da condição de proletarização.

O Movimento Occupy em Wall Street em 2011 traz para o centro dos protestos o sistema social vigente, notadamente a concentração da riqueza e do poder, condensados no centro financeiro de Nova York, o que ficou evidente no lema "somos $99 \%$ contra o 1\%". Sentido similar pensamos ter sido a mensagem das ruas em 2013 no Brasil - apesar das elites tentarem reduzir e manipular seu significado, de parte da esquerda ter ficado confusa e das múltiplas temáticas e perspectivas simultaneamente presentes - o que vimos foi um profundo descontentamento com o instituído, a desigualdade social, a reivindicação por mais e melhores serviços públicos.

Para Rolnik as mobilizações de Junho de 2013 não surgiram no nada, mas do acúmulo de movimentos urbanos como o passe livre, os sem teto e o movimento estudantil. Para Maricato (2013) e Harvey (2013) estas mobilizações repuseram na pauta a questão urbana e o direito à cidade, pois estas se tornaram um grande negócio com a especulação imobiliária, agravada pelas obras da Copa e Olimpíadas. Moradia, transporte e serviços públicos transformados em mercadoria tornam as cidades lugares de segregação social, mas também cenário e o objeto das lutas por moradia, livre circulação, direito ao trabalho, educação e saúde.

Mas o que podemos aprender com estas mobilizações e com a experiência do MST? Como assinalamos anteriormente, são as contradições e TrabalhoNecessario - www.uff.br/trabalhonecessario; Ano 14, № 25/2016 
os limites do presente que movem a luta social e suas organizações. Elas nos ensinam que a luta de classes não acabou pois é a divisão do trabalho e da riqueza em classes que está na base da sociedade e dos conflitos sociais. Ensinam-nos ainda que as formas de luta e organização da classe são dinâmicas. A descoberta de novos produtos e regiões do planeta pelo capital é também a entrada das lutas sociais em novas regiões e temas, pois para onde vai o capital o conflito vai atrás (SILVER, 2005). As formas de lutas, de mobilização e organização da classe, ainda que com muitas limitações, respondem às metamorfoses do capital. Por exemplo, a educação transformada em mercadoria ${ }^{6}$ - o que não é apenas sua privatização direta, tem feito emergir um conjunto de movimentos e mobilizações ao redor do globo que não cabem na estrutura sindical, mas criam novas formas de luta $e$ protestos como as ocupações de escolas iniciadas em São Paulo e neste momento espalhadas em todo o Brasil, a articulação de professores no México, as mobilizações estudantis no Chile. Mas também dão nova força às formas clássicas de luta, como as greves de professores no Brasil em anos recentes.

As mobilizações de massa e os novos coletivos a emergiram também indicam os limites da luta institucional e uma enorme crise de representação política no Estado e mesmo nas organizações de esquerda (HARVEY et all, 2012; MARICATO el all, 2013; CAROS AMIGOS, 2016). Quanto ao Estado, penso que vai se tornando transparente sua condição de classe e a submissão dos governos e parlamentos a poderosos interesses internacionais e locais, interesses estes que cada vez mais contrariam as necessidades e perspectivas da população que os elege. Guardo um otimismo proveniente desta constatação, pois se esta informação não é nova, o novo é que esta verdade vai se tornando evidente para as multidões, assim como a origem imoral e ilegal da acumulação da riqueza e a necessária pobreza econômica e cultural daí gerada, além do papel do Estado neste processo. Parece-me possível identificar uma dupla direção dos movimentos contemporâneos quanto ao Estado, de um lado uma "negação do Estado", de sua incapacidade de resolver os problemas da população, levando a auto-organização para sanar os problemas e a busca pela construção de alternativas; de outro, uma "afirmação

\footnotetext{
${ }^{6}$ Sobre isto ver Freitas, 2014.

TrabalhoNecessario - www.uff.br/trabalhonecessario; Ano 14, № 25/2016
} 
do Estado", a pressão para que se volte aos serviços públicos, aos direitos e políticas sociais e ao destino público dos recursos públicos.

Quanto à crise de representação dentro da própria esquerda, se destaca o questionamento à institucionalização das estratégias de luta, à hierarquização e concentração de poder, à burocratização sindical, fazendo emergirem coletivos que buscam exercer relações horizontais (CAROS AMIGOS, 2016), os quais identificam a política e as relações de poder em todos os locais, porém nem sempre devidamente articulados às estruturas centrais de poder ou à macro estrutura social. A esquerda não morreu, mas os jovens nas ruas e suas novas formas de luta e política indicam que esta condenada ao fracasso a esquerda institucionalizada, burocratizada, fortemente hierarquizada e já sem diálogo com suas bases. Em tempos difíceis e complexos como o atual, os movimentos juvenis revigoram os ânimos da luta social, apontam para a necessidade da esquerda se renovar, questionam as estruturas sociais e seus parâmetros de educação. Entre os movimentos juvenis se exercita hoje um pouco da liberdade que se deseja ampliar. É um lugar onde velhos e jovens radicais (IANNI, 1968) podem se encontrar.

O MST é um movimento social importante para a reflexão aqui proposta pois ele possui uma atualidade impressionante ao emergir da contradição central da sociedade: a propriedade privada dos meios de produção e com ela a necessária produção de uma massa que jamais será chamada à produção. Um movimento social que articula a luta econômica e institucional (MÉSZÁROS, 2002). A ocupação e o acampamento são questionamentos à propriedade privada e ao individualismo burguês, além de aglutinarem temas atuais como gênero, saúde, educação, meio ambiente, trazendo à tona a totalidade social, a articulação das partes no todo. Porém, a base material que se segue aos acampamentos, os assentamentos, não superam a lógica capitalista, mas contraditoriamente a repõe. A construção de relações humanas e de produção para além do capitalismo é o desafio não apenas do MST mas de toda humanidade. Está reposta então a clássica questão do primado da base material sobre a consciência. É preciso produzir a existência de um modo radicalmente novo para que a educação emerja diferente.

Construir novas formas de produção da vida, para além da forma burguesa, é um desafio tão complexo quanto necessário. Além da 
incorporação pelo capital dos elementos que buscam constituírem-se como novos, não haveria aspectos que Ihe escapam? A forma social superior a capitalista não estaria a emergir nos movimentos juvenis e culturais, nas periferias urbanas e no campo, nos ensaios de produção da vida para além do capital? Como na "Parada do Velho Novo" de Brecht (1987), o novo nasce e entremeia-se ao velho, ora se destaca, ora se confunde. Não seríamos nós que ainda precisamos aprender a ver e ajudá-lo a nascer?

O MST e diversos movimentos recentes indicam que a formação humana se processa tendo por base a realidade objetiva, as condições de vida, as relações que estabelecemos. Neste sentido a educação não é um processo individual, mas coletivo, e é na organização coletiva para superação da sociedade atual que pode emergir um novo sentido à educação. A formação para uma nova sociedade só pode ser dar na luta pela contestação do estabelecido, tendo por base as contradições sociais e a tentativa de construção de novas formas de vida social. A consciência de classe é produto das lutas da classe, portanto da prática social. $O$ discurso e a fala tem poder educativo desde que sintonizados com o real. A educação formal também pode contribuir neste processo quando ocupada e articulada às lutas. Os movimentos sociais educam para o novo na medida em que apontam concretamente para este novo. É a luta radical que permite abrir novos horizontes para o futuro da sociedade e também para a educação.

\section{Referências Bibliográficas}

ALVES, G. Ocupar Wall Street... e depois? In: HARVEY, D. et all. Occupy: movimentos de protestos que tomaram as ruas. São Paulo: Boitempo e Carta Maior, 2012.

BRECHT, B. Poemas 1913 - 1956. $3^{\text {a }}$ ed. São Paulo: Brasiliense, 1987.

CARNEIRO, H. S. Rebeliões e Ocupações de 2011. In: HARVEY, D. et all. Occupy: movimentos de protestos que tomaram as ruas. São Paulo: Boitempo e Carta Maior, 2012.

CAROS AMIGOS ESPECIAL. Novas Esquerdas. Ano XIX, n. 80, São Paulo, 2016.

CPT. Conflitos no Campo Brasil 2015. Goiânia: CPT Nacional, 2016. Disponível em: http://www.cptnacional.org.br/ Acesso em 13/9/2016 as 15:33 hs. 
DALMAGRO, S. L. A escola no contexto das lutas do MST. Tese (Doutorado em Educação). Florianópolis: UFSC, 2010.

DAVIS, M. Planeta Favela. São Paulo: Boitempo, 2006.

FERNANDES, F. A revolução burguesa no Brasil: ensaio de interpretação sociológica. $5^{\text {a }}$ ed. São Paulo: Globo, 2006.

FIGUEIRA, P. de A. A educação de um ponto de vista histórico. INTERMEIO Revista do Mestrado em Educação - UFMS. Campo Grande, v. 1, n. 1, 1985.

FREITAS, L. C. de Os empresários e a política educacional: como o proclamado direito à educação de qualidade é negado na prática pelos reformadores empresariais. In: Germinal: Marxismo e Educação em Debate, Salvador, v. 6, n. 1, p. 48-59, jun. 2014.

FONTES, V. O Brasil e o capital-imperialismo: teoria e história - 3 ed. Rio de Janeiro: EPSJV/Editora UFRJ, 2010.

GRADE, M. MST: luz e esperança de uma sociedade igualitária e socialista. Florianópolis: UFSC, Dissertação (Mestrado em Economia), 2000.

HARVEY, D. A liberdade da cidade. In: MARICATO, E. et all. Cidades Rebeldes: passe livre e as manifestações que tomaram o Brasil. São Paulo: Boitempo e Carta Maior, 2013.

HARVEY, D. O novo imperialismo, 8ª ed. São Paulo: Loyola, 2014.

HARVEY, D. et all. Occupy: movimentos de protestos que tomaram as ruas. São Paulo: Boitempo e Carta Maior, 2012.

IANNI, Otávio. O jovem radical. In: BRITTO, Sulamita de (org.) Sociologia da Juventude I: da Europa de Marx à América Latina de hoje. Rio de Janeiro: Zahar, 1968.

IANI, O. Origens Agrárias do Estado Brasileiro. São Paulo: Brasiliense, 2004.

JAMESON, F. Pós-modernismo: a lógica do capitalismo tardio. São Paulo, Ática, 2006.

KULA, W. La historia económica y la historia de los novos movimientos sociales. In: Problemas y métodos de la historia economica. Barcelona: Península, 1977, p. 68-71.

LUKÁCS, G. Marxismo ou existencialismo. São Paulo: Senzala, 1967.

MANACORDA, M. A. Marx e a pedagogia moderna. Campinas, Editora Alínea, 2007.

MARICATO, E. et all. Cidades Rebeldes: passe livre e as manifestações que tomaram o Brasil. São Paulo: Boitempo e Carta Maior, 2013.

MARICATO, E. É a questão urbana, estúpido! In: MARICATO, E. et all. Cidades Rebeldes: passe livre e as manifestações que tomaram o Brasil. São Paulo: Boitempo e Carta Maior, 2013. 
MARX, K. O Capital: Crítica da economia política. $17^{\text {a }}$ ed. Livro 1, vol. 1. Rio de Janeiro: Civilização Brasileira, 1999.

MARX, K. e ENGELS, F. A ideologia alemã. São Paulo: Martins Fontes, 1989.

MARX, K. e ENGELS, F. Textos sobre Educação e Ensino. São Paulo: Centauro, 2004.

MÉSZÁROS, I. Para além do capital: por uma teoria da transição. São Paulo: Boitempo Editorial, 2002.

MÉSZÁROS, I. A educação para além do capital. São Paulo: Boitempo Editorial, 2005.

PINASSI, M. O. Balanço dos 30 anos do MST. Correio da Cidadania. São Paulo, 9 mar. 2014.

SAPELLI, M. L. S. S. Escola do Campo - espaço de disputa e de contradição: análise da proposta pedagógica das Escolas Itinerantes do Paraná e do Colégio Imperatriz Dona Leopoldina. $448 \mathrm{f}$. Tese (Doutorado em Educação). UFSC: Florianópolis, 2013.

SILVER, B. Forças do trabalho: movimentos de trabalhadores e globalização desde 1870. São Paulo: Boitempo, 2005.

SUCHODOLSKI, B. Teoria marxista da educação. vol. 3. Lisboa: Editorial Estampa, 1976.

SUCHODOLSKI, B. A pedagogia e as grandes correntes filosóficas: a pedagogia da essência e a pedagogia da existência. São Paulo: Centauro, 2002.

THOMPSON, E. P. A formação da classe operária inglesa. Rio de Janeiro: Paz e Terra, 1987. 3 v.

VENDRAMINI, C. R. Terra, trabalho e educação: experiências sócioeducativas em assentamentos do MST. Ijuí: Editora da Unijuí, 2000.

VENDRAMINI, C. R. A natureza de classe dos trabalhadores sem-terra. In: AUED, B. e PAULILO, M. I. S. (org.). Agricultura familiar. Florianópolis: Insular, 2004. (p. 217 - 227).

ZIZEK, S. Problemas no Paraíso. In: MARICATO, E. et all. Cidades Rebeldes: passe livre e as manifestações que tomaram o Brasil. São Paulo: Boitempo e Carta Maior, 2013. 